Fixed Point Theory, 19(2018), No. 1, 219-224

DOI 10.24193/fpt-ro.2018.1.17

http://www.math.ubbcluj.ro/ ${ }^{\text {nodeacj/sfptcj.html }}$

\title{
RANDOM NASH EQUILIBRIUM
}

\author{
OSKAR GÓRNIEWICZ
}

Faculty of Mathematics and Information Science

Warsaw University of Technology

E-mail: oskgor@gmail.com

Abstract. In this paper the notion of random n-persons game is defined. The most important problem of such games is the existence of Random Nash Equilibrium (RNE) which is defined in section 4. Since not every random game has RNE, we will consider here a subclass of random games called admissible random games. Finally, using a generalized version of Kakutani's theorem it is proved that for any admissible random game there exists a RNE.

Key Words and Phrases: Nash equilibrium, random fixed points, multivalued operators.

2010 Mathematics Subject Classification: 91A02, 47B80, 47H40, 47H04, 47H10.

\section{REFERENCES}

[1] J. Andres, L. Górniewicz, Random topological degree and random differential inclusions, Topol. Meth. Nonlinear Anal., 40(2013), no. 2., 337-358.

[2] E.J. Balder, On the existence of Cournot-Nash equilibrium in continuum games, J. Math. Economy, 32(1999), 207-223

[3] I. Barany, S. Vempala, A. Vetta, Nash equilibria in random games, Random Structures and Algorithms, 31(2007), 391-405.

[4] B. Bogusławska-Kregiel, L. Górniewicz, A. Kasprowicz, R. Skiba, Proba eliminacji wypuklosci w problemach ekonomicznej rownowagi, Roczniki Naukowe WSB, 1(2007).

[5] K. Borsuk, Theory of Retracts, Polish Sci., 1967.

[6] I.L. Glicksberg, A further generalization of the Kakutani fixed point theorem, with application to Nash equilibrium points, Proc. Amer. Math. Soc., 3(1952), 170-174.

[7] L. Górniewicz, Topological Fixed Point Theory of Multivalued Mappings, Springer, 2006.

[8] A. Haurie, J. Krawczyk, G. Zaccour, Games and Dynamic Games, World Sci Pub. Co. Pte. Ltd, 2012.

[9] A. Jakiewicz, A.S. Nowak, Stochastic games with unbounded payoffs: applications to robust control in economics, Dyn Games Appl., 253(2011), no. 1, 253-279.

[10] S. Kakutani, A generalization of Brouwer's fixed point theorem, Duke Mathematical J., 8(1941), 457-459.

[11] E. Maskin, Nash Equilibrium and Welfare Optimality, Harvard University, 1998.

[12] R.B. Myerson, Refinements of the Nash equilibrium concept, Int. J. Game Theory, 73(1978), no. $7,73-80$.

[13] J.F. Nash, Non-Cooperative Games, Annals of Mathematics, 54(1951), 286-295.

[14] A.S. Nowak, On stochastic games in economics, Math. Meth. Oper. Res., 66(2007), 513-530

The project was financed by funds of National Science Center granted by decision number DEC2013/11/B/HS4/00857; carried out at Warsaw University . 
[15] A. Wiszniewska-Matyszkiel, Belief distorted Nash equilibria: introduction of a new kind of equilibrium in dynamic games with distorted information, Annals of Oper. Research, 243(2016), $147-177$.

[16] N.C. Yannelis, A. Rustichini, Equilibrium points of non-cooperative random and Bayesian games, In: Positive Operators, Riesz Spaces, and Economics. Studies in Economic Theory, vol 2. Springer, Berlin, Heidelberg, 23-48.

Received: October 26, 2016; Accepted: November 28, 2016. 